American Journal of Applied Sciences 6 (4): 582-585, 2009

ISSN 1546-9239

(C) 2009 Science Publications

\title{
Complexes of 2-Thioacetic Acid Benzothiazole with Some Metal Ions
}

\author{
${ }^{1}$ Emad Yousif, ${ }^{2}$ Yang Farina, ${ }^{1}$ Khawla Kasar, ${ }^{2}$ Abdualbasit Graisa and ${ }^{1}$ Kumail Ayid \\ ${ }^{1}$ Department of Chemistry, College of Science, Al-Nahrain University, Baghdad, Iraq \\ ${ }^{2}$ School of Chemical Science and Food Technology, Faculty of Science, \\ University Kebangsaan Malaysia, 43600UKM Bangi, Selangor DE Malaysia
}

\begin{abstract}
New metal complexes of the ligand 2-thioacetic acid benzothiazole with the metal ions $\mathrm{Ni}(\mathrm{II}), \mathrm{Cu}(\mathrm{II}), \mathrm{Zn}(\mathrm{II}), \mathrm{Cd}(\mathrm{II})$ and $\mathrm{Sn}(\mathrm{II})$ were prepared in alcoholic medium. The prepared complexes were characterized by FTIR Spectroscopy, electronic spectroscopy, ${ }^{1 \mathrm{H}} \mathrm{NMR},{ }^{13 \mathrm{C}} \mathrm{NMR}$, magnetic susceptibility and conductivity measurements. From the spectral measurements, monomer structures for the complexes were proposed. Square planar geometry was proposed for the copper complex. The other complexes were proposed to be tetrahedral.
\end{abstract}

Keywords: thioacetic acid, benzothiazole; metal complexes

\section{INTRODUCTION}

Increasing physiological importance of Oxygen donor organic compounds ${ }^{[1]}$ and active role played by coordination certain metal ions to them ${ }^{[2]}$ have interested use in synthesizing and studying structural aspects of metal complexes with some oxygen, sulphur and nitrogen donor ligands ${ }^{[3]}$.

The aromatic benzothiazole nucleus is associated with a variety of antihistamine activity ${ }^{[4]}$, pharmacological actions $^{[5]}$ such as fungicidal ${ }^{[6]}$ and leishmanicides activities ${ }^{[7]}$. These activities are probably due to the presence of the $-\mathrm{N}=\mathrm{C}-\mathrm{S}$ group. Substituted benzothiazole have been reported to display diverse applications as photostablizer and metal complexing agents ${ }^{[8,9]}$.

The wide range of application of the ligand and its metal complexes aroused our interest to prepare a new series of some metal complexes.

\section{MATERIALS AND METHODS}

Synthesis of 2-thioacetic acid benzothiazole: A mixture of 2-mercapto benzothiazole $(0.1 \mathrm{~mole})$ and chloroacetic acid $(0.1$ mole) in presence of $\mathrm{KOH}$ as a basic media was refluxed for $3 \mathrm{~h}$ to give 2-thioacetic benzothiazole $\left(\mathrm{L}_{\mathrm{H}}\right)$, the white yellow precipitate which formed was filtered and crystallized from ethanol to give the final product.

The steps of the synthesis of 2-thioacetic benzothiazole can be shown below.
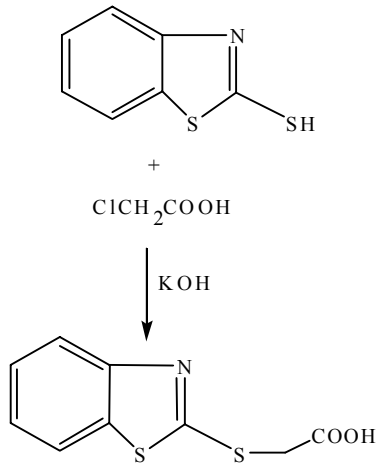

Preparation of complexes: Addition of ethanol solution of the suitable metal salt (Nickel acetate tetrahydrate, Tin chloride, Copper acetate, Cadmium acetate dihydrate and Zinc acetate dihydrate) to an ethanol solution of 2-thioacetic acid benzothiazole in 2:1 (ligand: metal) molar ratios was carried out. After reflux for half an hour, crystalline colored precipitates formed at room temperature. The rustling solids were filtered off, washed with distilled water, dried and recrystallized from ethanol and dried at $50^{\circ} \mathrm{C}$. Table 1 shows the melting point of the prepared compounds.

Instrumentation: Elemental $\mathrm{C}, \mathrm{H}, \mathrm{N}$ and $\mathrm{S}$ analysis were carried out on a Fison EA 1108 analyzer, the FTIR spectra in the range $(4000-200) \mathrm{cm}^{-1}$ cut were recorded as CsI disc on FTIR.8300 Shimadzu Spectrophotometer, uv-visible spectra were measured using Shimadzu Uv-vis. 160 A-Ultra-violet Spectrophotometer in the range $(200-1000) \mathrm{nm}$. The magnetic susceptibility values of the prepared 
Am. J. Applied Sci., 6 (4): 582-585, 2009

Table 1: Physical data for preparation ligand and the complexes

\begin{tabular}{|c|c|c|c|c|c|c|}
\hline \multirow[b]{2}{*}{ Compound } & \multirow{2}{*}{$\begin{array}{l}\text { Melting } \\
\text { point }{ }^{0} \mathrm{C}\end{array}$} & \multicolumn{4}{|c|}{ Found(Calcd)\% } & \multirow[b]{2}{*}{ M } \\
\hline & & $\mathrm{C}$ & $\mathrm{H}$ & $\mathrm{N}$ & $\mathrm{S}$ & \\
\hline $\mathrm{L}_{\mathrm{H}}$ & $177-179$ & $48.11(47.98)$ & $3.21(3.13)$ & $6.45(6.22)$ & $29.2(28.47)$ & - \\
\hline $\mathrm{Ni}(\mathrm{L})_{2}$ & $141-143$ & $24.99(24.62)$ & $1.98(2.38)$ & $5.42(5.52)$ & $25.12(25.29)$ & $12.17(11.57)$ \\
\hline $\mathrm{Cu}(\mathrm{L})_{2}$ & $180-182$ & $33.67(24.22)$ & $2.23(2.36)$ & $5.36(5.47)$ & $25.19(25.05)$ & $12.38(12.41)$ \\
\hline $\mathrm{Zn}(\mathrm{L})_{2}$ & $161-163$ & $42.65(42.07)$ & $2.35(2.35)$ & $5.64(5.45)$ & $24,88(24.96)$ & $12.81(12.72)$ \\
\hline $\mathrm{Cd}(\mathrm{L})_{2}$ & $145-147$ & $37.65(38.54)$ & $2.23(2.16)$ & $5.23(4.99)$ & $23.32(22.86)$ & $19.89(20.04)$ \\
\hline $\mathrm{Sn}(\mathrm{L})_{2}$ & $350-352$ & $38.84(38.11)$ & $2.54(2.13)$ & $4.87(4.94)$ & $2.2 .75(22.61)$ & $21.17(20.93)$ \\
\hline
\end{tabular}

complexes were obtained at room temperature using Magnetic Susceptibility Balance of Bruke Magnet B.M.6, Atomic absorption measurements of the prepared complexes were obtained using Shimadzu 680cc-flame.

The $1 \mathrm{H}$ and $13 \mathrm{C}$ nuclear magnetic resonance spectra were recorded on a jeol $400 \mathrm{MHz}$ spectrometer in dueteated DMSO, relative to the internal standard Tetramethylsilane (TMS). Melting points were recorded on a hot stage Gallen Kamp melting point apparatus.

\section{RESULTS AND DISCUSSION}

Infra-red spectroscopy: The ligand was prepared by the reaction of one mole of 2-mercapto benzothiazole with one mole of chloroacetic acid in presence of $\mathrm{KOH}$.

Table 1 shows the physical data for the ligand and the prepared complexes. The data of CHNS and metal analysis were obtained using flame atomic absorption technique. The calculated values were in a good agreement with the experimental values.

The FTIR spectrum of the ligand, shows a characteristic stretching absorption bands at 3435, 1710, 1573 and $694 \mathrm{~cm}^{-1}$ assigned to hydroxyl, carbonyl, $\mathrm{C}=\mathrm{N}$ of the thiazole ring and the stretching of $\mathrm{C}-\mathrm{S}$ group respectively .

The reaction between this ligand with $\mathrm{Ni}$ (II), $\mathrm{Cu}$ (II), $\mathrm{Zn}$ (II), Cd (II) and Sn (II) gave different types of complexes. In the free ligand, the bands at 1710 and $1033 \mathrm{~cm}^{-1}$ were assigned to the stretching of $\mathrm{C}=\mathrm{O}$ and $\mathrm{C}-\mathrm{O}$ of the hydroxyl in the carboxylate group. On complexation these bands were shifted to a lower frequency region.

This shift is probably due to the complexation of the metal to the ligand through oxygen of the carbonyl group, the disappearance of the hydrogen from hydroxyl group on complexation indicate the complexation is through the oxygen atom. Stretching of metal-oxygen bands of the complexes appeared in low frequency region $(412-440) \mathrm{cm}^{-1[10]}$.

The IR data of the complexes are shown in Table 2. The Table lists the stretching frequency (v) for some of the characteristics groups exhibited by the ligand and complexes.
Table 2: Characteristic absorption bands of 2-thioacetic acid benzothiazole and its complexes

\begin{tabular}{llll}
\hline Compound & $v(\mathrm{C}=\mathrm{O}) \mathrm{cm}^{-1}$ & $v(\mathrm{C}-\mathrm{O}) \mathrm{cm}^{-1}$ & $v(\mathrm{M}-\mathrm{O}) \mathrm{cm}^{-1}$ \\
\hline $\mathrm{L}_{\mathrm{H}}$ & 1710 & 1033 & - \\
$\mathrm{Ni}(\mathrm{L})_{2}$ & 1590 & 1002 & 440 \\
$\mathrm{Cu}(\mathrm{L})_{2}$ & 1670 & 985 & 412 \\
$\mathrm{Zn}(\mathrm{L})_{2}$ & 1564 & 995 & 428 \\
$\mathrm{Cd}(\mathrm{L})_{2}$ & 1569 & 979 & 435 \\
$\mathrm{Sn}(\mathrm{L})_{2}$ & 1660 & 985 & 414 \\
\hline
\end{tabular}

Table 3: Electronic spectra for 2-thioacetic acid benzothiazole and its complexes in DMSO solvent

\begin{tabular}{|c|c|c|c|c|}
\hline Compound & Color & $\begin{array}{l}\text { Absorption } \\
\text { bands (nm) }\end{array}$ & & $\begin{array}{l}\text { Assigned } \\
\text { transition }\end{array}$ \\
\hline $\mathrm{L}_{\mathrm{H}}$ & Yellow & $282 \quad 301$ & 328 & $\pi \rightarrow \pi^{*}$ \\
\hline $\mathrm{Ni}(\mathrm{L})_{2}$ & Pale green & $\begin{array}{r}281 \\
\quad 460\end{array}$ & 301 & $\begin{array}{l}\pi \rightarrow \pi^{*} \\
{ }^{3} \mathrm{~A}_{2} \rightarrow{ }^{3} \mathrm{~T}_{1}(\mathrm{p})\end{array}$ \\
\hline $\mathrm{Cu}(\mathrm{L})_{2}$ & Green & $\begin{array}{r}296 \\
610\end{array}$ & 308 & $\begin{array}{l}\pi \rightarrow \pi^{*} \\
{ }^{2} \mathrm{~B}_{1} \mathrm{~g} \rightarrow{ }^{2} \mathrm{~A}_{1} \mathrm{~g}\end{array}$ \\
\hline $\mathrm{Zn}(\mathrm{L})_{2}$ & Pale Yellow & 301 & 330 & $\pi \rightarrow \pi^{*}$ \\
\hline $\mathrm{Cd}(\mathrm{L})_{2}$ & White & $280 \quad 290$ & 300 & $\pi \rightarrow \pi^{*}$ \\
\hline $\mathrm{Sn}(\mathrm{L})_{2}$ & White & 284 & 302 & $\pi \rightarrow \pi^{*}$ \\
\hline
\end{tabular}

Ultraviolet-visible spectroscopy: The ultraviolet visible electronic spectrum of the 2-thioacetic acid benzothiazole $\left(\mathrm{L}_{\mathrm{H}}\right)$ in DMSO solvent is recorded in Table 3. Bands at the wavelengths $(282,301$ and 328 $\mathrm{nm})$ This transition may be attributed to $\pi \rightarrow \pi^{*}$ electronic transition $^{[11]}$.

The electronic spectra of 2-thioacetic acid benzothiazole complexes showed, as expected, different absorptions from that of the free ligand. In the complexes these bands were shifted to different wavelength than the corresponding bands in the ligand as shown in Table 3, which appears in the wavelength range between $280-381 \mathrm{~nm}$.

The ligand field electronic transitions between the metal d orbital's appear in $\mathrm{Ni}$ (II) and $\mathrm{Cu}$ (II) bands located in the visible region at $460 \mathrm{~nm}$ for $\mathrm{Ni}(\mathrm{L})_{2}$ assigned to the transition ${ }^{3} \mathrm{~A}_{2} \rightarrow{ }^{3} \mathrm{~T}_{1}$ (p) and $610 \mathrm{~nm}$ for $\mathrm{Cu}(\mathrm{L})_{2}$ assigned to the transitions ${ }^{2} \mathrm{~B}_{1} \mathrm{~g} \rightarrow{ }^{2} \mathrm{~A}_{1} \mathrm{~g}$. The other complexes were diamagnetic as expected for $\mathrm{d}^{10}$ ions, so that no (d-d) transition can be expected in the visible region

Magnetic susceptibility and conductivity measurements: The experimental magnetic moment 
Am. J. Applied Sci., 6 (4): 582-585, 2009

Table 4: Magnetic Moment, Conductivity measurements in DMF solvent

\begin{tabular}{lllll}
\hline Symbol & Name & Conductivity $\mathrm{ohm}^{-1} \mathrm{~cm}^{2} \mathrm{~mol}^{-1}$ & Magnetic moment (B.M) & Suggested structure \\
\hline $\mathrm{Ni}(\mathrm{L})_{2}$ & Bis(2-thioacetic acid benzothiazol) nickel(II) & 12 & 3.11 & Tetrahedral \\
$\mathrm{Cu}(\mathrm{L})_{2}$ & Bis(2-thioacetic acid benzothiazol)copper(II) & 19 & 1.44 & Square Planner \\
$\mathrm{Zn}(\mathrm{L})_{2}$ & Bis(2-thioacetic acid benzothiazol) zinc(II) & 10 & 0.00 & Tetrahedral \\
$\mathrm{Cd}(\mathrm{L})_{2}$ & Bis(2-thioacetic acid benzothiazol) cadmium(II) & 15 & 0.00 & Tetrahedral \\
$\mathrm{Sn}(\mathrm{L})_{2}$ & Bis(2-thioacetic acid benzothiazol) tin(II) & 10 & 0.00 & Tetrahedral \\
$\mathrm{L}_{\mathrm{H}}$ & 2-thioacetic acid benzothiazol & - & - & - \\
\hline
\end{tabular}

for each metal complexes is listed in Table 4. Magnetic measurements are widely used in studying transition metal complexes. The magnetic properties are due to the presence of unpaired electrons in the partially filled d-orbital in the outer shell of these elements. These magnetic measurements give an idea about the electronic state of the metal ion in the complex.

The magnetic moment for $\mathrm{Ni}$ (II) in any complex is approximately 3.11 B.M., this value refers to a high spin tetrahedral structure, while the value of $\mathrm{Cu}$ (II) is approximately 1.44 led to suggest the square planar structure which can become in a good agreement with the data of electronic transitions. Other complexes have no magnetic moment because its diamagnetic. Molar conductivity measurement in DMF solvent at $25^{\circ} \mathrm{C}$ showed that the complexes were non-electrolyte ${ }^{[11]}$ Table 4.

NMR spectroscopy: The data of proton NMR of the 2thioacetic acid benzothiazol and its complexes displayed good solubility in DMSO. The proton nuclear magnetic resonance spectral data gave additional support for the composition of the complexes, Table 5 .The observed changes are evidences of complexion had happened because the chemical shift of a compound is heavily depended on its electronic environment.

The ${ }^{1 \mathrm{H}} \mathrm{NMR}$ spectrum of the complexes confirmed the disappearance of $\mathrm{OH}$ signal at $12.22 \mathrm{ppm}$ in the free ligand. The $\delta 7.35-8.14 \mathrm{ppm}$ resonance signal protons of the aromatic ring shifted to the higher field upon complexation, while the proton of the $-\mathrm{CH}_{2}$ aliphatic group shifted to higher field also ${ }^{[12]}$.

The ${ }^{13 \mathrm{C}} \mathrm{NMR}$ of the ligand and its complexes are presented in Table 6 . The $\mathrm{C}=\mathrm{O}$ resonance group of the complexes at 158.46-159.6 $\mathrm{ppm}$ where shifted downfield compared with the position in the free ligand which appeared at $196.51 \mathrm{ppm}$. It is most likely that shift is due to the decrease of electron density at carbon atoms when oxygen is bonded to metalion ${ }^{[12]}$.

Study of complex formation in solution: Complexes of (L) with metal ions were studied in solution using ethanol as a solvent, in order to determine $[\mathrm{M} / \mathrm{L}]$ ratio in the complex follow Molar ratio method ${ }^{[13]}$.
A series of solutions were prepared having a constant concentration $\left(10^{-3} \mathrm{M}\right)$ of the metal ion and (L).

Table 5: ${ }^{1 \mathrm{H}} \mathrm{NMR}$ spectral data $(\delta, \mathrm{ppm})$ of the ligand and complexes

\begin{tabular}{llll}
\hline Symbol & $-\mathrm{OH}$ & $-\mathrm{CH}_{2}$ aliphatic & Aromatic \\
\hline $\mathrm{Ni}(\mathrm{L})_{2}$ & - & 4.16 & $6.35-7.14$ \\
$\mathrm{Cu}(\mathrm{L})_{2}$ & - & 4.22 & $6.45-7.87$ \\
$\mathrm{Zn}(\mathrm{L})_{2}$ & - & 4.24 & $6.35-7.94$ \\
$\mathrm{Cd}(\mathrm{L})_{2}$ & - & 4.23 & $6.55-7.78$ \\
$\mathrm{Sn}(\mathrm{L})_{2}$ & - & 4.18 & $6.65-7.87$ \\
$\mathrm{~L}_{\mathrm{H}}$ & 12.22 & 4.19 & $7.35-8.12$ \\
\hline
\end{tabular}

Table $6:{ }^{13 \mathrm{C}} \mathrm{NMR}$ spectral data $(\delta, \mathrm{ppm})$ of the ligand and complexes

\begin{tabular}{llll}
\hline Symbol & $\mathrm{C}=\mathrm{O}$ & aliphatic & Aromatic \\
\hline $\mathrm{Ni}(\mathrm{L})_{2}$ & 159.64 & 28.34 & $121.34-115.65$ \\
$\mathrm{Cu}(\mathrm{L})_{2}$ & 158.64 & 28.46 & $121.22-114.23$ \\
$\mathrm{Zn}(\mathrm{L})_{2}$ & 158.76 & 29.43 & $121.07-114.43$ \\
$\mathrm{Cd}(\mathrm{L})_{2}$ & 159.32 & 28.53 & $121.15-115.17$ \\
$\mathrm{Sn}(\mathrm{L})_{2}$ & 158.46 & 29.47 & $121.13-114.06$ \\
$\mathrm{~L}_{\mathrm{H}}$ & 169.51 & 30.30 & $121.22-114.26$ \\
\hline
\end{tabular}

The $[\mathrm{M} / \mathrm{L}]$ ratio was determined from the relationship between the absorption of the absorbed light and the mole ratio of $[\mathrm{M} / \mathrm{L}]$. The results of complexes formation in solution.

The results of complexes in ethanol, suggest that the metal to ligand ratio was [1/2] for all complexes which were similar to that obtained from solid state Study.

On the basis of the preceding discussion, the structure of the complexes suggested as follows:

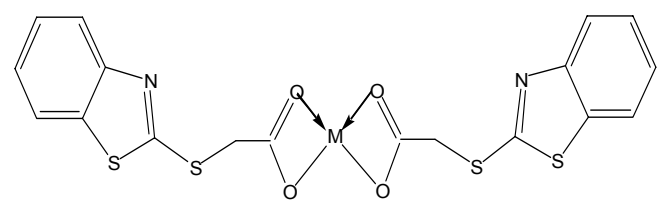

CONCLUSION

The ligand 2-thioacetic acid benzothiazole were successfully synthesized by condensation method. The ligand was treated to different metal salts to afford the corresponding complexes. Square planar geometry was proposed for the copper complex. The other complexes were proposed to be tetrahedral. 
Am. J. Applied Sci., 6 (4): 582-585, 2009

\section{REFERENCES}

1. Wang, F.Q., W.J. Zhuang and L.P. Jin, 2007. Selfassembly and structure of three new $\mathrm{Zn}$ (II) complexes with pyrazine-2, 6-dicarboxylic acid. J. Mol. Struct., 832: 48-54. DOI: 10.1016/J.Molstruc.2006.08.012.

2. Deka, K., N. Barooah, R.J. Sarma and J.B. Baruah, 2007. Self-assembled carboxylate complexes of zinc, nickel and copper. J. Mol. Struct., 827: 44-49. DOI: 10.1016/J.Molstruc.2006.05.005.

3. Zeinab, H., Abd El-Wahab, 2007. Mononuclear metal complexes of organic carboxylic acid derivatives: Synthesis, spectroscopic characterization, thermal investigation and antimicrobial activity. Spectr. Acta, 67: 25-38. DOI: 10.1016/J.Saa.2006.05.038.

4. Brzezin, E., G. Kos'kaa, and K. Walczyn'skib, 2003. Application of thin-layer chromatographic data in quantitative structure-activity relationship assay of thiazole and benzothiazole derivatives with $\mathrm{H}$-antihistamine activity. J. Chrom., A 1007: 145-155. DOI: 10.1016/S0021-9673(03)00951-8.

5. Rana, A., N. Siddiqui, S. Khan, S. Haque and M. Bhat, 2008. N-\{[(6-Substituted-1,3benzothiazole-2-yl) amino]carbonothioyl $\}-2 / 4-$ substituted benzamides: Synthesis and pharmacological evaluation. Eur. J. Med. Chem., 43: 1114-1122. 10.1016/J.Ejmech.2007.07.008.

6. Huang, W. and G. Yang, 2006. Microwave assisted, one pot syntheses and fungicidal activity of polyfluorinated 2-benzylthiobenzothiazoles Bio. Med. Chem., 14: 8280-8285. DOI: 10.1016/J.Bmc.2006.09.016.
7. Ram, V., U. Singha, and P. Guru, 1990.Chemotherapeutic agents XI: Synthesis of pyrimidines and azolopyrimidines as leishmanicides. Eur. J. Med. Chem., 2: 533-538. DOI: 10.1016/0223-5234(90)90148-V.

8. Tellez, F., V. Pena-Hueso, N. Barba-Behrens, R. Contreras, and A. Flores-Parra, 2006. Coordination compounds in a pentacyclic aromatic system from 2-aminobenzothiazole derivatives and transition metal ions. Polyh., 25: 2363-2374.DOI: 10.1016/J.Poly.2006.03.003.

9. Pinheiro, S., J. de Sousa, M. Santiago, I. Carvalho, A. Silva, A. Batista, E. Castellano, V. Ram, U. Singhab and P. Gurub, 1990. Chemotherapeutic agents XI: Synthesis of pyrimidines and azolopyrimidines as leishmanicides. Eur. J. Med. Chem., 25: 533-538. DOI: 10.1016/02235234(90)90148-V.

10. Nakamoto, K., 1997. Infrared of Inorganic and Coordination Compounds. 5th Edn., John Wiely, New York, pp: 400. ISBN-10: 0471163929.

11. Sutton, D. 1968. Electronic Spectra of Transition Metal Complexes. McGraw- Hill, London.

12. Sliverstien, R., G. Bassler, and T. Morrill, 2005. Spectrometric Identification of Organic Compounds. 7th Edn., John-Wiley, New Yor, pp: 500. ISBN: 978-0-471-39362-7.

13. Douglas, S., W. Donald, F. Holler and S. Crouch, 2003. Fundamentals of Analytical Chemistry. 8th Edn., Saunders College, New York, pp: 1168. ISBN-10: 0030355230. 